\title{
ENHANCING STUDENT MOTIVATION IN ESP BY INCREASING THE LEVEL OF ENGAGEMENT: A PROPOSED MODEL
}

\author{
Albena Stefanova and Georgi Zabunov \\ University of National and World Economy, \\ Sofia, Bulgaria
}

\begin{abstract}
The article considers the opportunity to enhance student motivation in the acquisition of English for specific purposes by increasing the level of learner engagement. The authors propose to use an interdisciplinary approach by applying tools that have been approved in marketing theory and practice for the management of consumer involvement in the purchasing process and adapting them to teaching ESP to increase course effectiveness. Marketing literature analysis reveals two important points. The first one is that in classical marketing, the concepts of enduring involvement and situational involvement are used and combined together to form a complex consumer response. In modern marketing, this complex response is called consumer engagement. The second point is that situational involvement plays a key role in shaping the complex consumer response. The authors' suggestion is to use situational involvement as the major tool for boosting student motivation taking into consideration factors such as the specific features of the new generations and the growing use of modern technologies in everyday communication and learning. A description of model tasks is given to exemplify their interdisciplinary nature as well as observations related to their use in class supplemented by student feedback.
\end{abstract}

Keywords: ESP, learning motivation, student engagement, enduring involvement, situational involvement

Article history:

Submitted: 2 May 2020

Reviewed: 4 May 2020

Revised: 17 November 2020

Accepted: 15 December 2020

Published: 21 December 2020

\author{
Contributor roles: \\ Conceptualization; Investigation; Methodology; Data curation; \\ Formal Analysis; Project Administration: A.S., G. Z. (equal); \\ Resources, Supervision, Visualization: G.Z. (lead); \\ Writing original draft, Writing - review and editing: A.S. (lead)
}

Copyright (C) 2020 Albena Stefanova and Georgi Zabunov

This open access article is published and distributed under a CC BY-NC 4.0 International License which permits non-commercial use, distribution, and reproduction in any medium, provided the original author and source are credited. Permissions beyond the scope of this license may be available at albena.stefanova@unwe.bg. If you want to use the work commercially, you must first get the authors' permission.

Citation: Stefanova, A., \& Zabunov, G. (2020). Enhancing Student Motivation in ESP by Increasing the Level of Engagement: A Proposed Model. English Studies at NBU, 6(2), 201-216.

https://doi.org/10.33919/esnbu.20.2.2

Albena Stefanova is a Senior Lecturer at the University of National and World Economy, Sofia, Bulgaria, and has a PhD in methodology of teaching modern languages. She has been teaching English to students of philosophy, policing, law, economics, and political studies for over twenty years. Her main interests are in ESP and translation.

E-mail: albena.stefanova@unwe.bg

https://orcid.org/0000-0002-9757-3221

Georgi Zabunov is an Associate Professor at the University of National and World Economy, Sofia, Bulgaria, and has a PhD in Marketing. He teaches Real estate Business. His research interests are in the field of Consumer behaviour, Real estate Marketing, Real estate Market Analysis, Property management and Facility management.

E-mail: georgi_zabunov@unwe.bg

https://orcid.org/0000-0002-5981-1372 


\section{Engagement in Learning and Consumer Behaviour}

Throughout centuries thinkers have stressed the importance of engagement for learning effectiveness. Engagement is indicative of the way people learn and at the same time reveals important aspects of the learning process and education. It is key to knowledge acquisition, however, in this article it is seen as the common term combining consumer involvement and student engagement which ensures a systematic approach that, based on marketing and education strategies, enhances motivation and hence the acquisition of language and subject matter. Along with the consideration of motivation in education by highlighting the major motivators, strategies and factors contributing to effective learner performance, the authors examine the concept of involvement related to the field of marketing and consumer behaviour.

Marketing theory and practice are constantly evolving. In a marketing context, the concept of involvement was used until the end of the previous century. Then, the concept of engagement was developed. The change was due to the introduction of information and communication technologies in business which led to a shift in the focus of research from the analysis of the characteristics of individual consumers to the analysis of large databases in a highly technological environment. The present study aims to find tools for a close contact with students and for possibilities for individual impact on them. This is why we used mostly marketing techniques from the times of classical marketing, i.e. until the end of the $20^{\text {th }}$ c. Along with this, the continuity between classical and modern approaches is indicated. To avoid terminological inaccuracies in the article, the concept of involvement is used in terms of the research of classical marketing and the concept of engagement is used in terms of modern ESP.

In essence, marketing is not just a set of techniques intended to generate sales at any cost. It is one of the major social achievements of the $20^{\text {th }}$ century. It is a tool people and organisations use in order to achieve their goals through voluntary, informed and mutually beneficial exchange with other stakeholders (Kotler, 2000).

This accumulated marketing knowledge, from the 1950s to the end of the last century, we propose, can be applied to increase engagement in learning. Thus, through the synergy of interdisciplinary psychological concepts, some improvements are suggested to achieve educational optimisation. Focused on the tertiary level and taking 
into account the requirements for a modern course in English for economics and facility management, in particular, the authors pay attention to the introduction of novel teaching techniques and strategies aimed at provoking student interest, increasing the student perceived value of specialised knowledge and skills, and facilitating the language acquisition process.

\section{Motivation and Engagement in Learning}

Motivation is crucial for the successful achievement of a goal or performance of an activity. It is a system of motives based on needs, interests, objectives, ideals and aspirations. Without motivation, no activity can be conducted or, if performed, its quality and stability are doubtful. In the field of learning, no goal can be achieved without motivation for learning because learners will not make efforts to learn anything proficiently. Therefore, learners who are highly motivated have higher chances to learn better (De Bot et al., 2005). Crookes and Schmidt (1991) defined motivation as 'interest in and enthusiasm for the materials used in class; persistence with the learning task, as indicated by levels of attention or action for an extended duration; and levels of concentration and enjoyment' (as cited by Majetić, 2013, p. 263). Motivation is influenced by factors of different nature: extrinsic and intrinsic motives. The former are related to the performance of activities followed by a reward or praise, whereas the latter are associated with needs satisfaction and the activity itself as a reward (Folmer \& Hoberg, 1993, as cited by Neikova, 2015). The motivation that is based on intrinsic factors is defined as engagement. 'Engagement may be defined as students' cognitive investment, participation with, and emotional commitment to learning particular content' (Bender, 2017, p. 2) In foreign language learning, extrinsic factors are mostly related to professional realisation in terms of a better position, salary, environment, etc. Intrinsic are the factors concerning the process of language acquisition such as methods of teaching, teacher personality, learning success. Based on the motives for foreign language learning and the abovementioned factors, it is possible to speak of two major types of motivation- instrumental and integrative. According to Gardner (1985), the former is related to the pragmatic reasons that make an individual study a language, while the latter involves the positive attitude to becoming familiar with and adapting to the culture of the nation whose language is being learned. 
In order to ensure the effective acquisition of specific language knowledge and skills, student engagement must be encouraged and enhanced. Students should be stimulated to actively participate in the learning process and improve language performance. If they are highly motivated and highly engaged in the learning process, the acquisition of any subject matter will be increasingly successful. Student engagement is considered an important involvement in the process of learning, which Kearsley and Schneiderman see as the contribution of three components: learning through collaboration, project-based work and an authentic focus (Kearsley and Schneiderman, 1998). Insufficient engagement leads to low achievement, frustration and boredom. Engagement is a multifaceted concept and has three key components: cognitive engagement - related to the degree of student involvement and investment in learning; behavioural engagement - related to student behaviour in social, academic and co-curricular contexts; and emotional engagement - related to the reactions to learning environment including teachers, classmates, institutional climate, etc. An insightful approach to this concept is the focus on its effect or as Ashwin and McVitty put it 'on what is being "formed" through student engagement' (Ashwin \& McVitty, 2015, p. 345). Thus, they distinguish 'engagement to form individual understanding, engagement to form curricula and engagement to form communities' (Ashwin \& McVitty, 2015, p. 345). Furthermore, Ashwin and McVitty consider the degrees of student engagement and speak of consultation, partnership and leadership (Ashwin \& McVitty, 2015), i.e. students are seen as co-creators.

When discussing motivation and engagement, we find it important to consider modern generations of learners (generation $\mathrm{Z}$ and Millennials), also called digital natives, and contemporary social and learning contexts. Millennials learn in a little different way than their parents. They grow up with modern technologies and have a strong interest in interactive, dynamic and visual technologies, which impacts the way they perceive and learn. Moreover, this reflects on their needs, communication and behaviour, which represents another challenge to learning effectiveness as well as to course design and teaching approaches. In terms of foreign language education for specific purposes, this means introducing novel techniques, different authentic materials, inventing new and more interactive tasks and enhancing teacher-student cooperation in the process of learning. Based on Windham (2005) who thinks that in 
order to engage students in learning, new courses must include interaction, exploration, relevancy, multimedia and instruction, Parsons and Taylor (2011) synthesize these categories and add one more - authentic assessment, thus paying attention to the changes in assessment that are needed in order to match the changes in course design and teaching approaches.

Research on late millennials in generation $\mathrm{Z}$ reveals very interesting trends. These young people are sensitive in terms of security and are oriented towards a good career which does not involve risk taking. For instance, of all surveyed age groups the youngest (aged 19-30 as of 2019) are least willing to take part in a start-up company or to become entrepreneurs (Brown, 2020). It is, therefore, reasonable to approach such learners using the techniques for capricious customers and to attract them by applying established business practices.

\section{The Concept of Involvement in Marketing Science}

Within the context of the study of consumer behaviour, the concept of involvement was not easily accepted in theory and practice. Before it became an object of research in business, this phenomenon had been studied by social psychology in the context of persuasive communications (Sherif \& Sherif, 1967). The authors discussed the so-called "ego-involvement" and studied its characteristics and measurements. The first to use the concept of involvement was Herbert Krugman (Krugman, 1965) who also pointed out the key role of involvement in effective convincing communication not only in marketing but in general as well. However, Krugman noted the complexity of the influence mechanisms of involvement. The practical use of involvement must be based on in-depth research rather than obvious correlations. Marketing practitioners showed considerable interest in Krugman's ideas and he deepened his research by suggesting the first adequate instruments for involvement measurement (Krugman, 1967). In the end of the 1960s this issue became one of the crucial ones to understanding consumer behaviour (Howard \& Sheth, 1969). As a matter of fact, the three cited authors Krugman, Howard and Sheth outlined the terminology accepted today and defined the contemporary content of the concept of involvement. In specialised literature, the term felt involvement is defined as the psychological experience of the motivated consumer (Celsi, R. \& Olson, 1988). Thus, felt involvement can be enduring, situational, cognitive, or affective (Richins et al., 1992). Enduring involvement exists when the surveyed 
individuals show strong interest in a given object or activity over a long period of time. The reason for this is the conscious relation between the object or activity and an important individual need. Most often, consumers experience situational or temporary involvement with an object or activity. In these cases, the level of involvement is determined by the characteristics of a particular situation. For instance, a young man who is not interested in conservative clothes can feel a high level of involvement in the particular situation of buying a suit for a job interview (Houston \& Rothschild, 1978). Another important distinction is the one between cognitive and affective involvement (Park \& Young, 1986). We talk of cognitive involvement when the surveyed person is highly motivated to process information about an object or activity - to look for new facts, to consider the present ones, etc. Affective involvement, on the other hand, means that the surveyed individuals have strong emotions towards objects and/or activities.

To understand involvement, scientists consider it crucial to determine the relation between enduring and situational involvement for the ultimate level of involvement is the result of the interaction of these two dimensions. Such an understanding implies not only the definition of the concepts but also the identification of approaches for the measurement of their impact, i.e. an adequate measurement.

This task seems simple only at first glance. Enduring involvement reflects individual's value orientation and psychology offers various tools for their identification and measurement. However, this is not the case with situational involvement. Generally, it cannot be measured directly and is implied by the presence of certain behaviours regarding an object of interest (in marketing, this is a given product class). Situational involvement never manifests itself alone because enduring involvement exists over time, i.e. in some cases there is enduring involvement only, whereas in other cases there are both enduring and situational involvement at the same time. But it is impossible to observe situational involvement only. This is the reason why it is not possible to directly measure its impact at an individual level. Therefore, situational involvement reveals the general trend for a particular situation to generate some average level of response among a huge number of individuals (Houston \& Rothschild, 1978). Thus, even though the level of situational involvement of a given individual in a particular situation cannot be measured directly, it is possible to evaluate the trend of a particular situation to lead to a similar overall response complexity within a group of individuals. 
Enduring involvement is an ongoing concern with an object (product). It is considered a function of past experience with the object and the extent to which the object is related to the individual's value of orientation (Houston \& Rothschild, 1978). In specialised literature, there are different interpretations of the nature of the relation between enduring and situational involvement as well as of the way their combination leads to different involvement responses. However, the empirical studies with statistically valid results are few. One of the most reliable ones was carried out in 1992 (Richins et al., 1992) and its results are indicative. The objects of research were the following products: new automobiles, winter clothes and suits. They all require serious consideration throughout the purchasing process and involve the evaluation of the risks related to this process which are of both of financial and social nature (bad decisions can influence social status negatively). The most interesting finding of this study is the fact that the initial levels of enduring involvement neither suppress, nor increase the situational effects occurring around purchase. Based on the statistical analysis of the collected empirical data, it made the authors suggest a simple additive model of interaction between situational and enduring involvement. This means that involvement response complexity is always proportionate to situational involvement but with respectively lower and higher intensity for low and high enduring involvement. Therefore, it is important to take this pattern into account in the selection of approaches aimed at increasing engagement in the learning process.

Based on the review of the classical marketing literature, it can be concluded that what in the previous century was considered the result of involvement is regarded as engagement in modern marketing. In particular, the intensity of an individual's participation in and connection with an organisation's offerings and/or organisational activities, which either the customer or the organisation initiate (Vivek et al., 2012).

Measuring involvement is complex itself and its clarification is beyond the scope of the present discussion. Generally, it is appropriate to apply direct affective response for the measuring of enduring involvement. A good rating scale to measure involvement is Charles Osgood's semantic differential. When examining situational involvement, it is important to measure the overall group trend for similar actions. Furthermore, it must be taken into consideration that enduring involvement manifests itself at the same time. A good measure is the use of formulated by the researcher statements for which the 
respondent expresses a degree of agreement, indifference or a degree of disagreement. The most common scales are the seven-point ones, but five-point scales are applicable as well. Statements must be formulated in such a way as to concern the behavioural, affective, and cognitive components of respondents' attitudes. If they are well prepared, questionnaires can be used to measure both enduring and situational involvement, i.e. engagement. An example of consumer engagement measuring is suggested by Vivek et al. (2014). Developing an adequate questionnaire will be of key importance for the measurement of student engagement. What is more, if such a questionnaire is available, a teacher will be able to measure engagement in the beginning of the course. Then, having applied various educational tools and techniques, the teacher can measure engagement in the end of the course. This will allow the language professional to see if the educational tools and techniques lead to increased engagement. Thus, the learning process can be constantly improved by taking into consideration the learners' individual characteristics.

\section{Proposed Model for Enhancing Engagement in Learning}

Given the changes in the mindset of the new generations and the latest developments in contemporary society, including globalisation, new technology and EU educational policy aimed at promoting high quality education and training, several suggestions are made to improve the quality of the educational product offered by universities to students of economics. These suggestions are aimed at increasing student engagement and thus enhancing student motivation. Enhanced learner motivation will, therefore, contribute to boosted performance in a more original and novel way if an interdisciplinary approach is used based not only on the acquisition of English for specific purposes, but also on marketing. Applying marketing techniques in the process of language acquisition can lead to greater curiosity and hence to boosted engagement as well as to deeper satisfaction and hence to improved performance. Student engagement is considered the same as consumer involvement. Thus, increasing engagement, a teacher can work with more motivated learners and obtain better results through a more effective course. This is in line with the generally accepted revised definition of ESP proposed by Dudley-Evans and St. John (1998) including absolute and variable characteristics underlying the importance of the specific subject matter and respectively of the specific educational needs to be met. The ESP for students of 
economics has all absolute and variable characteristics in terms of specific learner needs, methodology and specific linguistic competences (absolute characteristics) on the one hand, and in terms of subject specificity, specific situations, learner linguistic background and characteristics (variable characteristics), on the other.

Using the proposed interdisciplinary approach aimed at enhancing student engagement the authors suggest several novel techniques which could be introduced in the ESP course.

\section{Suggestion 1: Introduction of more interactive tasks}

Our first suggestion is the introduction of more interactive tasks based on the generations' flair for everyday use of social media and virtual communication combined with greater independence when choosing the databases to use and the way to process them. For instance, students are assigned tasks related to particular economic issues involving the search of information and its processing as well as critical thinking and at the same time contributing to the acquisition of specific knowledge and skills related to business communication and terminology. Focusing on the issue of joining EU's ERM II (Exchange Rate Mechanism), for example, students are supposed to find out more about the advantages and disadvantages of this mechanism and of the Euro zone and to consider the implications for Bulgaria. They are also expected to present their own position with justification based on the information they have processed and, finally, they are asked to prepare short presentations on the pros and cons. With tasks like these, students are encouraged to use their IT skills, imagination and creativity, and at the same time all key skills are developed and improved in a way providing selfdirection, stimulating autonomy and revealing the real value of the subject matter taught. The ESP practitioner is more a consultant here rather than a teacher, which contributes to a more relaxed environment in which students can be encouraged to take the initiative and lead more effectively. Finding and analysing reliable information is among the major requirements for a successful career in the area of economy where forecasts and awareness of processes and trends are crucial. Using marketing techniques to enhance enduring and situational involvement, on one hand and to increase cognitive and affective involvement, on the other, together with the novel tasks based on interaction, exploration, and multimedia aimed at increasing student engagement contribute to greater course effectiveness and communicative competence 
for we notice higher levels of the key components of engagement mentioned abovecognitive, behavioural, and affective. For example, to attract the attention of demanding customers, marketers use a combination of informative media advertising and offering small gifts at points of purchase. Advertising is designed to increase product knowledge and, consequently, enduring involvement. Accordingly, gifts evoke a positive emotional attitude, which leads to increased situational involvement. The result is a higher level of consumer engagement. In the learning process, the role of informative advertising is performed by traditional lectures of the teacher. Because for students the Internet is a place primarily for entertainment, educational films placed there are perceived as gifts. They diversify "boring" lectures and make learning material easier to understand.

\section{Suggestion 2: Project-Based Learning}

The second suggestion is related to projects. Projects are part of the everyday routine of a professional in any sector of the economy, so experience in project work organisation is an asset to an ESP course for students of economics and in line with the definition of the ESP course proposed by Carver (1983) according to which there are three major characteristics, namely authentic materials, specific purpose and selfdirection. Even though the projects prepared throughout an ESP course do not have all characteristics of a real project carried out in business life and are not something new, having in mind Project-Based Learning, they are novel in terms of structure, content and overall objectives and contribute to the balanced development and improvement of students' specialised skills for business communication in situations simulating real business environment and relations and thus leading to enhanced enduring and cognitive involvement.

An example is the most recent project our students were assigned which was entitled "The socio-political and economic implications of the COVID-19 pandemic". They were provided one common resource - an issue of "The Economist" from 14 March 2020. The project involved three tasks. The first one was a pair-work task where each pair had to read a section of the magazine and prepare a presentation on its particular topic. Students were also allowed to and encouraged to use any other reliable information that could provide updates or complement the information in the given section. The second task was more specific because it was related to the ESP courses offered at the university. Each student was given an article to summarise from the 
above-mentioned issue of "The Economist". There was a time limit of 30 minutes in class. Summarising is among the key components of the state exam students take at the end of their 2-year course in ESP. The state exam has two parts - written and speaking ones with the written one involving listening, reading, business writing, use of English and writing a summary in English of a specialised text which is in the source language and the oral one including the oral summary of an article in English followed by a discussion of the issue considered in the article as well as with questions on the specialised vocabulary in it. The summary in the second project task was oral and followed the pattern of the state exam. The third and last task was a speaking one. It involved reading the whole issue and then students were required to present their justified positions on the topic of their presentations, on the topic of their article and on the pandemic in general with the option to focus on a particular aspect. The project had strict deadlines for each task. At the end, all participants were encouraged to share their opinion on their fellows' performance and analyse it. Thus, through hands-on activities, using modern technology and social media they acquired specific competences of searching databases and finding reliable and appropriate information. Then they learned how to process it in terms of particular professional purposes by analysing and organising it to fit the assigned tasks and, last but not least, they developed specialised skills for presenting and expressing positions. Summarising was no longer perceived as something too difficult to deal with but seen as an opportunity to develop skills related to paraphrasing, to tackling linguistic problems, to realising the importance of translation, grammar, and professional language. Furthermore, at the end of the project, students were given the opportunity to comment their fellows' performance and to provide both negative and positive feedback. This enabled them to see their work from the perspective of consultants and assessors and to realise the nature of teacher work as well as to realise their own potential in terms of the perceived value of education and their ESP course. Similarly to promotions and sampling, learners became more motivated through increased involvement.

\section{Suggestion 3: Visits}

The third suggestion includes visits. The visits could be of two kinds but in both of them the language of communication is English. The first one involves the visit to the university of a distinguished professional in the area of economy who presents on a 
burning issue or focuses on an aspect of their work and talks about the institution they work for and the opportunities this institution gives such as internships, scholarships, business events. For instance, throughout the ESP course of the students who are finishing their 2-year language education now, they were visited by an expert from the Bulgarian National Bank. These academic visits can also involve the participation of alumni or 3- and 4-year students from the university who have already succeeded in their career and can share their experience with younger students, thus providing peer feedback and setting a good and inspirational example. The second kind of visit is a practical visit to a business, which provides the opportunity to see how it functions from the inside so that students can get insights into business activity in person. For example, the students of facility management visited one of the biggest business centres in the capital of Bulgaria, met its management and were familiarised with its operations and activity in detail. Getting to know the departments, the positions of the people in them and their responsibilities provides a first-hand experience that students found very useful and valuable. It increased their interest in the study of FM and once again showed them the potential of the knowledge of English for specific purposes which in turn contributed to their enhanced learning motivation related to both ESP and economics. During the visits, students meet with professionals who have already achieved high results in the profession. From them, they perceive the familiar ideas from traditional lectures in different ways. Thus, high-ranking professionals involved in the learning process play for students the role of celebrities from the advertisements that consumers try to emulate. In marketing, this makes it easier to convince consumers of the quality of the product. The result for students is a higher level of engagement.

\section{Suggestion 4: Free Sampling of a Product}

The fourth technique is borrowed directly from marketing and adapted for the purposes of the learning process. Free samples of a product are used to increase situational involvement as a tool for sales promotion. Having tested and, hopefully, approving of them, a consumer can start using them constantly. In piloting this approach, the students studying facility management were offered analyses of the object of study prepared in advance by the lecturer. These analyses help students do the assigned task easily. They show considerable interest in the suggested analysis techniques - regression analysis and data envelopment analysis (DEA). The students are 
attracted by the opportunity to use popular software such as Microsoft Excel for which there is a host of free educational materials on the Internet. Based on the analyses prepared and provided by the lecturer (an analogue of the free samples in marketing) students could acquire simple versions of the abovementioned techniques on their own. This required the acquisition of the scientific terminology of the techniques and the students manage to achieve it easily while they are learning using free educational films on YouTube.

\section{Conclusion}

Our observations have led to several conclusions. By applying an interdisciplinary approach, we propose novel techniques to the teaching of ESP by seeing the ESP course as an educational product that could be better marketed if advertised more adequately by convincing consumers in its quality and revealing the potential of the product features. This way we could increase consumer involvement, which in our case means student engagement, by enhancing enduring involvement and stimulating situational involvement and by boosting involvement response complexity or overall student engagement. Thus, we could achieve higher learning motivation and greater course effectiveness. We could also attempt to persuade learners why some tasks they find difficult, useless, or time-consuming are in fact a vital and indispensable part of their education as well as of their future successful career. Therefore, through increasing situational involvement we can make students with low level of engagement reconsider and increase it, hence contributing to the higher average student engagement.

Among the conclusions based on the authors' observations and an initial informal student feedback is the fact that using the suggested novel approach, we avoid the high risk and great uncertainty associated with situational involvement and manage to provoke greater student engagement by persuasion and positive emotions such as delegating power through giving the students the opportunity to be their peers' consultants, teachers and assessors throughout the course while preparing different tasks or working together. Furthermore, they get practical experience of what teamwork is about and prepare to work with partners from different backgrounds and of variable communicative competence but with whom they have common goals to achieve. Another advantage is that students realise the value of education in the long- 
term similarly to the purchase of durable goods such as homes or automobiles associated with higher consumer involvement or higher student engagement respectively. Marketing techniques could help to facilitate ESP acquisition by boosting motivation based on tasks like visits and projects similar to promotions involving free samples or test drives. Having perceived the benefits of the "product", learners can increase their performance and boost their knowledge of economic subject matter as well as of the practical real-life aspect of their future career. In the end of their ESP course, students would have acquired a higher average level of specific linguistic knowledge and skills and would have become more fluent in presenting, having small talks, negotiating, writing business letters, preparing reports or presentations and would have made considerable progress in processing information, working with databases and thinking critically which may provide evidence that the interdisciplinary approach has contributed to the appreciation of the competitive advantages of the educational academic products. This makes us think that the suggested interdisciplinary approach could contribute to the increased effectiveness of courses not only in English for specific purposes but in other subjects as well and thus have a greater contribution to the increased quality of education in general.

Tools borrowed from marketing practice and used to stimulate consumer involvement in the purchasing process can successfully be adapted in order to enhance student motivation to study ESP. Situational involvement exercises the highest influence on the overall response complexity which teachers could focus on. Considering ESP, a product allows the use of marketing techniques to increase educational quality. Deciding which marketing tools to apply in this case is a promising area of research. In order to use successfully the level of involvement as a factor for enhancement of student motivation, it is necessary to develop an adequate questionnaire for engagement measurement.

\section{References}

Ashwin, P., \& McVitty, D. (2015). The Meanings of Student Engagement: Implications for Policies and Practices. In: A. Curaj, L. Matei, R. Pricopie, J. Salmi, \& P. Scott (Eds.), The European Higher Education Area (pp. 343-359). Springer. https://doi.org/10.1007/978-3-319-20877-0 23 
Bender, W. (2017). 20 Strategies for Increasing Student Engagement. Learning Sciences International. https://www.learningsciences.com/product/20-strategies-forincreasing-student-engagement/

Bloch, P. (1981). An Exploration into the Scaling of Consumers' Involvement with a Product Class. In K. B. Monroe, \& A. Abor (Eds.), NA - Advances in Consumer Research, Volume 08 (pp. 61-65). Association for Consumer Research. https://www.acrwebsite.org/volumes/9786/volumes/v08/NA-08

Brown, D. (2020). Demographic Shifts: The World in 2030. Cushman \& Wakefield. http://info.cushmanwakefield.com/l/263412/2019-12-04/28v22b

Carver, D. (1983). Some propositions about ESP. The ESP Journal, 2(2), 131-137. https://doi.org/10.1016/0272-2380(93)90003-P

Celsi, R. L., \& Olson, J. C. (1988). The Role of Involvement in Attention and Comprehension Processes. Journal of Consumer Research, 15(2), 210-224. https://doi.org/10.1086/209158

Crookes, G., \& Schmidt, R. W. (1991). Motivation: reopening the research agenda. Language Learning, 41(4), 469-512. https://doi.org/10.1111/j.1467$\underline{1770.1991 . t b 00690 . x}$

De Bot, K.D., Lowie, W., \& Verspoor, M. (2005). Second Language Acquisition: An Advanced Resource book. Routledge. https://doi.org/10.4324/9780203446416

Dudley-Evans, T., \& St John, M. (1998). Developments in ESP: A multi-disciplinary approach. Cambridge University Press. https://doi.org/10.1016/S08894906(99)00026-5

Engin, A. O. (2009). Second language learning success and motivation. A journal of social behavior and personality, 37(8), 1035-1042. https://doi.org/10.2224/sbp.2009.37.8.1035

Gardner, R. C. (1985). The social psychology and second language learning: the role of attitudes and motivation. Edward Arnold. https://doi.org/10.1037/h0083787

Gass, S. M., \& Selinker, L. (2008). Second Language Acquisition: An Introductory Course. Routledge. https://doi.org/10.4324/9780203932841

Harmer, J. (1991). The Practice of English Language Teaching. Longman.

Houston, M. J., \& Rothschild, M. L. (1978). Conceptual and Methodological Perspectives on Involvement. In S. Jain (Ed.), Research Frontiers in Marketing: Dialogues and Directions (pp. 184-187). American Marketing Association.

Howard, J.A., \& Sheth, J.N. (1969). The Theory of Buyer Behavior. Journal of the American Statistical Association, January 1969, 467-487. https://doi.org/10.2307/2284311

Kearsley, G., \& Shneiderman, B. (1998). Engagement theory: A framework for technology-based teaching and learning. Educational Technology 38(5), 20-23. https://nazaliache.blogspot.com/2015/12/engagement-theory-frameworkfor.html

Kotler, P. (2000). Marketing Management, Millennium Edition (10th ed.). Prentice-Hall. 
Krugman, H. (1965). The Impact of Television Advertising: Learning Without Involvement. Public Opinion Quarterly, 29(3), 349-356. https://doi.org/10.1086/267335

Krugman, H. (1967). The Measurement of Advertising Involvement. Public Opinion Quarterly, 30(4), 583-596. https://doi.org/10.1086/267457

Majetić, S. (2013). Descriptive and Qualitative Analyses of How the Lack of Motivational Strategies Can Bear Negative Consequences on Students' Learning Achievements. Asian Journal of Education and e-Learning (1)5, 262-267.

Neikova, M. (2010). Chuzhdoezikovo obuchenie za vyzrastni i izpolzvane na strategii za chetene na chuzhd ezik. Godishnik na departament "Chuzhdi ezitsi i literaturi", NBU [Adult language training and the use of foreign language reading strategies. Foreign Languages and Literature Yearbook]. Sofia: NBU.

Park, C. W., \& Young, S. M. (1986). Consumer Response to Television Commercials: The Impact of Involvement and Background Music on Brand Attitude Formation. Journal of Marketing Research, 23, (February), 11-24. https://doi.org/10.2307/3151772

Parsons, J., \& Taylor, L. (2011). Improving Student Engagement. Current Issues in Education, 14(1), 1-32. https://cie.asu.edu/ojs/index.php/cieatasu/article/view/745

Richins, M. L., Bloch, P. H., \& McQuarrie, E. F. (1992). How Enduring and Situational Involvement Combine to Create Involvement Responses. Journal of Consumer Psychology, September, 143-154. https://doi.org/10.1016/S10577408(08)80054-X

Sherif, C.W. \& Sherif, M. (1967). Attitude, Ego-Involvement, and Change. Greenwood Press.

Vivek, S. D., Beatty, S. E., Dalela, V., \& Morgan, R. M. (2014). A Generalized Multidimensional Scale for Measuring Customer Engagement. Journal of Marketing Theory \& Practice, 22(4), 401-420. https://doi.org/10.2753/MTP1069-6679220404

Vivek, Shiri D., Sharon E. Beatty, and Robert M. Morgan (2012). Customer Engagement: Exploring Customer Relationships Beyond Purchase. Journal of Marketing Theory \& Practice, 20(2), 127-149. https://doi.org/10.2753/MTP1069-6679200201

Windham, C. (2005). The Student's Perspective. In D. Oblinger \& J. Oblinger (Eds.), Educating the Net generation (pp. 5.1-5.16). EDUCAUSE. https://www.educause.edu/ir/library/PDF/pub7101.PDF 